\title{
Philosophical Inquiry into Social Informatics - Methods and Uses of Language
}

\author{
Rocío Riueda Ortiz, Henrik Herlau, and Leif Bloch Rasmussen \\ Central University, Bogotá, Colombia, rruedaortiz@yahoo.com \\ Copenhagen Business School, Denmark, lbr.inf@cbs.dk, herlau@cbs.dk
}

\begin{abstract}
This paper inquires into the possibility of the development of ICT at the Bottom of the Pyramid. Its focus is on philosophically founded methods and languages applicable on a universal and exemplary basis. The methods are taken to be based on abduction and sweeping-in-processes and the languages are taken to be based on categorical imperatives of Kant and the discourse ethics of Habermas/Apel. These 'taken to be's' are contrasted with Jacques Derrida's 'Deconstruction'. Paul Feyerabend's 'Against Method' as well as complexity theory. The explicated monological/dialogical and formal / procedural methods and languages together with its counterparts are used to start a sweeping-in-process on 'Social Informatics'.
\end{abstract}

Keywords: deconstruction, inquiry, method, language, philosophy, social informatics, sweeping-in-process

\section{Introduction - Questions Asked}

During 2003-2005 a lot of work has been carried out on ICT in a globalized world. At the Global Level: WSIS in Geneva and Tunis, UN ICT Task Force and ILO's Fair Globalization. At the European Level: Lisbon Strategy, Agenda for Key Technologies, i2010, Preparation of CIP and 7-the Framework Programme and Strategic Partnerships with other countries. The call for papers for HCC7 on Social Informatics can be seen as part of that work.

This paper will try to inquire into the philosophical foundation of Social Informatics and beyond. The questions asked in Social Informatics and HCC's may be taken to be based in a Western quest for Enlightenment. We therefore start with two of the most prominent formulators of that quest, Immanuel Kant in 1784 and Foucault in 1984. In What is Enlightenment?, Kant said: "Enlightenment is man's

Please use the following fornat when citing this chapter:

Ontiz, R. R., Herlau, H., Rasmussen, L. B., 2006, in IFIP International Federation for Information Processing, Volume 223, Social Informatics: An Information Society for All? In Remembrance of Rob Kling, eds. Berleur, J., Numinen, M. I., Impagliazzo, J., (Boston: Springer), pp. 417-430. 
release from his self-incurred tutelage. Tutelage is man's inability to make use of his understanding without direction from another. Self-incurred is this tutelage when its cause lies not in lack of reason but in lack of resolution and courage to use it without direction from another. Sapere Aude! 'Have courage to use your own reason!' - that is the motto of enlightenment."

Foucault responded 200 years later, that Enlightenment could be taken to be [11]: the art of not being governed quite so much by

- Dogma from the (Christian) scriptures

- Authorities

- Language and text from sciences (humanities, social and natural)

$\ldots$ in such a way that $[11$, p. 132] "The critical ontology of ourselves has to be considered not, certainly, as a theory, a doctrine, nor even as a permanent body that is accumulating; it has to be conceived as an attitude, an ethos, a philosophical life in which critique of what we are is at one and the same time the historical analysis of the limits that are imposed on us and an experiment with the possibility of going beyond them."

Thus we take the quest for Enlightenment to be an ongoing courageous process based on an endless search for better methods and uses of languages. That search also means for us the study of the conditions of possibility, in terms of Foucault, that each epistemology with its language and methods bring us a particular set of tools to create a kind of reality, a kind of world.

\section{On Method}

As a way of starting on the methods and uses language we take as a point of departure the fundamental foundations of pragmatism and studies in empirical idealism on scientific methods as expressed in the writings of Edgar A. Singer and C. West Churchman. They both tell us, that when we reach a conclusion after having exposed our ideas to the most severe test we can imagine, then we have done the best that inquiry can possibly accomplish.

"The only trouble with this telling, they say, is all the trouble in the world: How do we know we have exposed our ideas to the severest test? If we have bound ourselves by our thinking into one corner of reality, then we shall never expose ourselves to the really severe test. Instead, we shall wander aimlessly about in our own narrow muddle, thinking we are progressing, but getting nowhere at all. The possibility that we have become prisoners of our own concepts is a topic that demands a separate study in the next part."

In his search for methods Churchman uses the work of E.A.Singer (especially 'Experience and Reflection' [26] and 'Mind as Behavior' [25] to develop a methodology using induction, deduction, abduction and beyond in a process called the 'sweeping-in-process'. Churchman tells that there are four possible situations in this process, based on $[6, p .191]$ :

1. the object remains the same over the period of time in which the methods are used, as does the methods

2. the object fluctuates in while the methods does not

3. the object remains the same while the methods fluctuate

4. both fluctuate. 
"Our question of how the system should behave in each of the four conditions is thus Hegelian in kind: how can the over-observer be created?"

When we decide that a hypothesis on 'reality' is not consistent with a set of readings from our methods then we can choose among three strategies, [6, p.194]:

1. revise the hypothesis by adding new variables, or changing the functional form of the hypothesis;

2. revise the methods used in obtaining the hypothesis (including discarding one or more of them as being incorrectly used); or

3. tolerate the inconsistency until more evidence is available.

We may begin to sense the sweeping-in process of the Singerian Inquiring System as endless. One might for example take the third possibility: the object may be taken to be constant while the methods may be taken to fluctuate. Then the question will be: Can we have any certainty in that our catalogue of sciences and their measuring 'rods' should start with logic? And then we may 'conclude' in the words of Churchman [6, p. 196]: "At this point, those who hold precision and certainty as high values of inquiring system may feel that the whole foundation has slipped. Once the measuring system engages in the game of adjusting imagery, and hence data, to 'save' its view of the world, all fundamental control seems to be lost: there is no ultimate court of appeals. One has only to recall the very flexible and subtle strategies open to Ptolemaic geocentric theory to see how far this game can be extended.

But such a reaction arises out of the kind of parsimony that no longer is suitable as a criterion for the design of inquiring systems. The parsimony is based on the erroneous theory that authority or authorization is essential for design. The word 'authority' derives from the concept of leadership, a component of the system to which one can turn when in doubt. It is similar to the concept of control, which implies that a component can observe and correct the behavior of the system. But Singerian inquiring systems have no such component. Put otherwise, authority and control are pervasive throughout the system and have no location; the system is controlled, but no component is the controller. The idea has already been mentioned several times under the labels 'tactics' and 'strategies'; a tactical decision assumes an authority while a strategic decision does not. Thus a Singerian inquiring system must encompass the whole breath of inquiry in its attempt to authorize and control its procedures."

Our methodology thus begins with data or theory, collects data or theories, interprete them, find new opportunities for data and/or theories in other fields than originally aimed at, reaches out for 'conclusions' for action/experiments, stops, wonders, rests ... and: starts the journey again. During the process abduction plays a crucial role, as it makes it possible once in while to switch from a culture of logic to a culture of imagination. Abduction is part of the sweeping-in process in that it is not a systematic and logic method; rather it introduces intelligent guesswork and imagination. In that way abduction is using experiences, reflections and experimental actions in the sweeping-in process as the building blocks for qualitative shifts in methods and use of languages in search of a theory.

This demands the spirit of the artistic and heroic mood in our search for more complex methods.

Instead of assuming that there is a specific external reality upon which we can ground our efforts to know the world, Foucault, Derrida, Deleuze, mobilize metaphors such as flux to index the sense that whatever there is in the world can not 
be properly or finally caught in the webs of inquiry found in science. They talk of discourse to point to the methodological efforts to make and know limited moments in the fluxes that make up reality [18, p. 2-10]. For these post-structuralist thinkers making anything present implies that other but related things are simultaneously being made absent, pushed away from view; that presence is impossible without absence. Thus representations go along with something out there to represent and a lot more besides. Then, method, on the one hand, is not a more or less successful set of procedures for reporting on a given reality. Rather it is performative. It helps to produce realities. Nevertheless, there is a hinterland of realities, of manifest absences and otherness, resonance and patterns of one kind and other, already being enacted and it cannot ignore these.

Methods are not, and could never be, innocent, neutral or purely technical. In fact, method produces not only truths and non-truths, realities and non-realities, presences and absences, but also arrangements with political implications. In this framework, the complexity paradigm, which for us go further post-structuralism and Derridian strategy of knowing, subvert 'the method' by helping to remake methods -in plural- that imagine and participate in politics and other forms of knowing in novel and creative ways by escaping the postulate of singularity and responding creatively to a world that is taken to be composed of an excess of generative forces and relations. Other recent works inspired in STSS (science, technology and society studies) emphasized that scientific and technological knowledge does not evolve in a vacuum. Rather they participate in the social world, being shaped by it and simultaneously shaping it. For Latour, Wooglar, Callon and Law (STS researches), reality is not out there beyond ourselves, independent of our actions or perceptions, neither reality presents itself to us in definitive forms of relations. For them, it is not possible to separate (1) the making of particular realities; (2) the making of particular statements about those realities and (3) the creation of instrumental, technical and human configurations and practices because they are all produced together. So, reality is not independent of the methods that produce reports of reality.

That means that we need to unmake/deconstruct many of our methodological habits including the desire of certainty, security and universalism and the expectation for stable conclusions and universalism. Laws [18] says that method is not simply about the kinds of realities that we want to recognize or the kind of worlds we might hope to make. It is also and most fundamentally, about a way of being. It is about what kinds of social science we want to practise. And then, and as a part of this, it is about the kind of people that we want to be, about how we should live. So, method goes with ways of working, ways of being: happy, creative, generous, reflecting and cooperating.

Of course, new method also means that we need to create other-s language-s. One interesting possibility for us is provided for narratives, as a valid way of knowing. Narratives are the mediator that makes actions and their unity compatible. It is not merely a passive intermediary linking two distinct and pre-existing levels of reality (individual action with the story). Narrative mediation is situated in-between; it reveals both realities, individual and collective; and it does so by organizing the unexpected overflowing that, by renewing the action, reveals the existence of a story-already-there, which might have been concluded but which the actor opens and sets off again in an unexpected directions. 


\section{On Use of Language}

The use of the method of 'sweeping-in process' can also be used in a search for uses of language for the Quest for Enlightenment and the search for answers to our questions on Social Informatics.

Again Kant is taken as a point of departure. According to a recent inquiry Bordum [2] shows, that at least four formulations of Kant's Categorial Imperative can be identified:

\section{(1) The categorical imperative formulated as a principle of universalization}

I should never act except in such a way that I can also will that maxim should become a universal law. [16: 14, 402]

Act only according to that maxim whereby you can at the same time will that it should become a universal law. [16: 30, 421]

Act according to that maxim which can at the same time make itself a universal law. [16: 42, 437]

\section{(2) The categorical imperative formulated as a practical principle}

Now I say that man, and in general every rational being, exists as an end in himself and not merely as a means to be arbitrarily used by this or that will. He must in all actions, whether directed to himself or to other rational beings, always be regarded at the same time as an end. $[14: 35,428]$

Act in such a way that you treat humanity, whether in your own person or in the person of another, always at the same time as an end and never simply as a means. [14: 36, 429]

\section{(3) The categorical imperative formulated in relation to the kingdom of ends}

Therefore, every rational being must so act as if he were through his maxim always a legislating member in the universal kingdom of ends. [14: 43, 438]

Act in accordance with the maxims of a member legislating universal laws for a merely possible kingdom of ends. [14: 43, 439]

(4) The categorical imperative formulated as the absolute good will's selflegislation in analogy to the laws of nature

Act as if the maxim of your action were to become through your will a universal law of nature. ([14:30, 421]

Act according to maxims, which can at the same time have for their object themselves as universal laws of nature. [14: 42, 437]

And Bordum concludes [2, p. 854-5]: "When I state that the formulations of the categorical imperative are different, it is due to the fact that each of them is specially formulated with different referents. They are respectively formulated in relation to: (1) the rational self-legislating person himself or herself and to self-legislation as such, (2) other rational self-legislating persons both themselves and others, (3) an objective law that can unite all persons' rational self-legislation, (4) self-legislation in analogy with the laws of nature."

Habermas has questioned the monological and formal approach used by Kant, yet they acknowledge the importance of these four formulations as basic for further developments of languages for statements of truths. As Bordum writes, [2, p. 868]: 
"Habermas has two main objections to Kant's approach. The first is that it is monological and the second is that it is formal. Habermas's main improvements to Kant's theory are to give it a new dialogical (intersubjective) and procedural foundation."

The requirements for dialogical action may be found in four universal validity claims for a power-free communication (Jürgen Habermas: On the Pragmatics of Communication, [12, p. 22-23]):

a. uttering something intelligibly,

b. giving (the hearer) something to understand,

c. making herself thereby understandable, and

d. coming to an understanding with another person.

Agreement thus is based on recognition of the four corresponding validity claims: comprehensibility, truth, truthfulness, and rightness.

If these validity claims are not met, then any dialogue for mutual understanding breaks down. Bordum then states the following principles for discourse in a supplement to Kant's [2, p. 867-870]:

- the principle of discourse: 'Just those action norms are valid to which all possibly affected persons could agree as participants in rational discourse'

- the principle of universalization: 'For a norm to be valid, the consequences and side effects that its general observance can be expected to have for the satisfaction of the particular interests of each person affected must be such that all affected can accept them freely'

Karl-Otto Apel has inquired into Habermas' position in order to find out whether Habermas can be said to have the final word. Obviously - as might be expected the answer is no, yet he convincingly shows that this 'no' must be taken to be just a pause in the dialogue; a sort of safe and comforting resting place before the journey continues.

In an article on Habermas' theory of communicative use of language Karl-Otto Apel [1]: tries to think with Habermas against Habermas. The idea of Apel is that it is not possible to prove by empirical means these intuitive theses of validity claims in an ethical discourse. This is not possible as the empirical proof in itself presupposes similar validity claims.

In order to avoid such difficulties that Habermas experiences in trying to do empirical justice to his validity claims Apel suggests another strategy for the ultimate justification (German: Letztbegründung) of the validity claims (constituting norms of the ethical discourse). He suggests a strict reflection that incorporates the necessary presuppositions for any claim of truth.

Apel (in accordance with Habermas) makes the following distinctions on use of language:

- Openly Strategic Use of Language, as an alternative to

- Closed Strategic Use of Language, which is one kind of

- Instrumental Use of Language which are contrasted with

- Use of Language for Mutual Understanding

In the theory on communicative action Habermas proofs convincingly that the Closed Strategic Use of Language and Instrumental Use of Language works against use of languages for mutual understanding. But Apel asks if this proof also holds for Open Strategic Use of Language? Apel is of the opinion, that it is not possible to make such a proof [1, p. 275]: "The reason for this is that, in the case of OSUL, it is impossible to in principle to decide which use of language - the strategically 
rational or the consensually communicatively rational - is more fundamental, without appealing to controversial philosophical presuppositions concerning the rational norms of language. Indeed, it is impossible to decide whether there is a fundamental use of language at all.

This means that the question cannot be decided on the basis of a formal pragmatics, which ultimately aims to demonstrate the presuppositions of language use in an empirical-descriptive manner. However, my thesis is that the question can be decided on the basis of a universal pragmatics which understands itself as a transcendental pragmatics of language. Such a transcendental pragmatics does not back away from the problem of an ultimate reflexive justification of rationality - so it is also able to address the problem of the relations of dependence between different types of rationality."

It is here that we find a recognition of the priority of the consensualcommunicative rationality of argumentative discourse. And this may be taken by some to be a resting place, as we might formulate some important statements on Social Informatics.

\section{Sweeping-in-Process on Social Informatics}

We take Social informatics to refer to the interdisciplinary study of the design, uses and consequences of ICTs that takes into account their interaction with institutional and cultural contexts. Key ideas of Social Informatics [17]:

1. The context of ICT use directly affects their meanings and roles.

2. ICTs are not value neutral: their use creates winners and losers.

3. ICT use leads to multiple, and often paradoxical, effects.

4. ICT use has moral and ethical aspects and these have social consequences

5. ICTs are configurable; they are actually collections of distinct components.

6. ICTs follow trajectories and these trajectories often favor the status quo.

7. ICTs co-evolve during design/development/use (before and after implementation)

These few statements can be taken into the endless sweeping-in process on knowing Social Informatics. As a suggestion we start by taking a few examples as a starting point:

From Kant:

1. Social Informatics should never act except in such a way that Social Informatics can also will its maxims should become a universal law

2. Act in Social Informatics in such a way that you treat humanity, whether in your own person or in the person of another, always at the same time as an end and never simply as a means

3. Act in Social Informatics in accordance with the maxims of a member legislating universal laws for a merely possible kingdom of ends

4. Act in Social Informatics as if the maxims of your action were to become through your will a universal law of nature

From Habermas:

1. Just those action norms in Social Informatics are valid to which all possibly affected persons could agree as participants in rational discourse 
2. For a norm in Social Informatics to be valid, the consequences and side effects that its general observance can be expected to have for the satisfaction of the particular interests of each person affected must be such that all affected can accept them freely

From Apel

1. Use of language for mutual understanding is the only language applicable for Social Informatics

A dialogue on these few principle/maxims is what we are arguing for in the design and possibly needed re-construction of the methods and use of languages in Social Informatics. From there we may embark on a journey in order to de-construct Social Informatics. We may even go against methods and look for the art of not being governed quite so much by

- Dogma from the (Christian) scriptures

- Authorities

- Language and text from sciences (humanities, sociology, natural)

As said by Bertrand Russell on philosophy: "The goal of philosophy is to begin with something so obvious that it is nearly not worth mentioning and end with something so absurd that nobody will believe it."

\section{Twist of the Knife}

So, our journey on the quest for Enlightenment starts again; guided by Jacques Derrida [7, 8], Paul Feyerabend [10] and Eric Jantsch [15].

In the tradition, language is considered something neutral, transparent and essential that represents reality. That means that there is a natural relation between the field of worlds and the field of things. Actions, subjects and experiences are simply reflected by words. Sounds emitted by voice are the symbols of the soul, and the written words, symbols of the words emitted by voice. So, reality is understood as exterior of language, belong to a fixed order that language simply express.

Nevertheless, with the linguistic turn, language is criticized -as many other issues- and it is pointed out the role of the categorizations and divisions established for language and discourse, which defined reality. So the role of the language is important because the big changes that happen in the social interaction where new languages and 'games of languages' appear. For the philosophy of difference -and deconstruction- there is not any discourse which can be considered the 'center', synthesis or neutral point for a supposed unity or universality

Deconstruction consists in un-made, without destruction, a system of thoughts which is revealed as unique and/or, hegemonic and/or, dominant. Deconstruction implies put in question and under suspicious the authority of one term (male, black, poverty, richness) and the naturalization the other terms as subaltern, minority and otherness. So, deconstruction produces 'other', 'the other invisible, absent, silent'.

The first step in de-construction is to locate the historic (etymological) roots of the concepts involved in the theme under inquiry. This leads to the identification of pairs of opposites that might illuminate the theme in new and most often radically different perspectives. The next step then is to bring these pairs of opposites into broad daylight and dig deeper into their interrelationships. The third step is to show that these pairs of opposites are hierarchically related. As part of this third step he 
can show that any concept is bound to its historical context and will imply certain ways of dialogue and acting that excludes other potential ways of communicating and acting, experiencing and reflection. The fourth step is to bring disorder on these pairs of opposites and showing that communications and actions taken based on these hierarchical ordered pairs of opposites will lead to paradoxes and questions on how communications and actions might have been different - and could be different.

Then, for Derrida deconstruction produces 'otherness', 'other' which implies dialogue with that/those other/s, respect for their singularity. It is just to be fair with other, as a same way to be fair with ourselves. Deconstruction is not only a process of dissociation, disarticulation, or destruction; it is as Derrida says, a condition for 'construction', for invention, that means as a condition for an affirmation. In this comprehension of the deconstruction as commotion and reconstruction, deconstruction is not only an analytic strategy but an impulse that pushed us to other interpretation of experience, to other experience of the other far of the idea of a centered subjectivity which is ordered by one reason or logic of thought. In our critic to Kant and Habermas, we can say that their ideas are stated in the reason and its 'light' which of course, illuminate just some kinds of reality leaving in the darkness others. For instance, the principle of 'universalization' needs to be confronted with the concepts of situated/local and contextualized knowledge. But also we need deconstruct who defines the 'ends' of the humanity. Moreover, the principles centered in human being, need their others: environment, animals, machines. We do know that consensus and hegemonic discourses about reality are always connected with power (in science, culture, and politics). Our challenge is that dialogue for mutual understanding guarantees other kind of discourses, even some of them which are not considered rational (in the universal idea of Kant or rationality).

The de-construction of ICT-concepts and design-methods would thus be needed before we embark on the task of ICT from BOP, SI and ICT for Fair Globalization, even the terms themselves in the first place. Such deconstruction is an endless process which is followed by reconstruction and invention process as we pointed out before. That is why we cannot feel comfortable with concepts on ICT and Social Informatics. We always need an attitude of alert against the idea of a closed or unitarian truth about them. But we need a permanent dialogue 'with others' as well which allow us to reach that process of invention and reconstruction, even if we do not have consensus, even there is not total agreement, there will appear partial consensus, partial truths, that permit the movement.

Feyerabend wrote his book 'Against Method' as a reaction to all methodologies proposed by science, but especially the methods put forward by logical positivism, Karl Popper and Imre Lakatos. His trouble with these 'scientific methods' relates to the fact that any break through in science, especially in modern physics, come about by breaking away from any scientific methodology put forward at the time. It is his aim to show that it is not possible to find any universal methodology. Science and scientific method is for Feyerabend an ideology and just one form of knowing of the world. The scientific methods exist with their rituals without having any 'true knowledge' or even any better description of the world. This means that scientific methods cannot claim to be better or to be prioritized than any other form of methodology or knowledge. Therefore 'anything goes', any methods has its advantages and its backdrops.

Feyerabend then postulates that there is a close relationship between science and myth [10, p. 284]: "The two areas are very close. The massive dogmatism that I have 
described is not just a fact, but it also has an important function. Science would be impossible at all without it. 'Primitive' thinkers showed a better understanding of the nature of knowing than their 'enlightened' philosophical rivals. Thus it is necessary once again to inquire into our attitude towards myth, religion, magic, witchcraft and all the attitudes that rationalists should like to see eradicating from the surface of the earth (without even having looked upon them - a typical taboo-reaction.)"

\section{New Guiding Images}

Our sweeping-in-process thus far is trying to choose all the methods and languages put forward by Eric Jantsch [14], that shows a way out by combing different inquiring approaches with spaces in which we inquire. Jantsch starts by defining three inquiring approaches [14, p.84ff]:

- The rational approach assumes separation between the observer and the observed, and focuses on an impersonal 'it' which is supposed to be assessed objectively and without involvement by an outside observer; the basic organizing principle here is logic, the results are expressed in quantitative or structural terms, and the dynamic aspects are perceived as change

- The mythological approach establishes a feedback link between the observer and the observed, and focuses on the relationship between a personal ' $\mathrm{I}$ ' and a personal 'Thou.' Its basic organizing principle is feeling, the results are obtained in qualitative terms, and the dynamic aspects are perceived as process, or order of change.

- The evolutionary approach establishes union between the observer and the observed and focuses on the 'we', on the identity of the forces acting in the observer and the observed world; the organizing principle is 'tuning-in' by virtue of this identity, and the results are expressed in terms of sharing in a universal order of process (namely, evolution).

All three approaches are part of our world and are taken to elucidate different aspects of it. They constitute but partial aspects of a multifaceted subject/object relationship as it is evoked most suggestively in a thirteenth century Japanese parable: "Two monks were arguing about a flag. One said: 'The flag is moving.' The other said: 'The wind is moving.' The sixth patriarch happened to be passing by. He told them: 'Not the wind, not the flag; mind is moving.' Wind, flag, mind move. The same understanding. When the mouth opens, all are wrong."

Jantsch defines three spaces in which we might be taken to inquire [14, p. 50-1]:

- physical space where man lives like other creatures

- social space which is created through differentiation, through the design of social roles and systems of such roles as they come into being with all kinds of social invention and innovation... Labor and task-sharing, crafts and industries, trade and accumulation of wealth, government and education, physical and conceptual mobility, collective health and organized fighting - they are all social inventions with their corresponding patterns and systems of roles

- spiritual space that holds man's relations with the numinous; his quest for purpose, direction, and meaning; his cultural inventions from values to religions, from the arts to philosophy and science. 


\begin{tabular}{|c|c|c|c|}
\hline & $\begin{array}{l}\text { GROUNDING } \\
\text { (Physical Space) }\end{array}$ & $\begin{array}{c}\text { SOCIALIZATION } \\
\text { (Social Space) }\end{array}$ & $\begin{array}{l}\text { INDIVIDUATION } \\
\text { (Spiritual Space) }\end{array}$ \\
\hline $\begin{array}{l}\text { EVOLUTIONARY } \\
\text { LEVEL }\end{array}$ & $\begin{array}{l}\text { Tao of the } \\
\text { " Earth } \\
\text { Vitalism } \\
\\
\end{array}$ & $\begin{array}{l}\text { Tao of Man } \\
\text { Humanity } \\
\text { Legitimacy } \\
L i \text {, ethics of } \\
\text { whole systems }\end{array}$ & $\begin{array}{l}\text { Tao of Heaven } \\
\text { Shunyata } \\
\text { God Within } \\
\text { Man-becoming- } \\
\text { in-universe- } \\
\text { becoming } \\
\text { Self-realization } \\
\text { Alchemy }\end{array}$ \\
\hline $\begin{array}{l}\text { MYTHOLOGICAL } \\
\text { LEVEL }\end{array}$ & $\begin{array}{l}\text { Gestalt } \\
\text { Animism } \\
\text { Magic }\end{array}$ & $\begin{array}{l}\text { Polytheistic } \\
\text { religions } \\
\text { Morality } \\
\text { Individual } \\
\text { ethics }\end{array}$ & $\begin{array}{l}\text { Monotheistic } \\
\text { religion } \\
\text { Virtue }\end{array}$ \\
\hline $\begin{array}{l}\text { RATIONAL } \\
\text { LEVEL }\end{array}$ & $\begin{array}{l}\text { Regularities } \\
\text { Natural Laws } \\
\text { Physical } \\
\text { technology }\end{array}$ & $\begin{array}{l}\text { Behavioral laws } \\
\text { Ceremony } \\
\text { Social } \\
\text { technology }\end{array}$ & $\begin{array}{l}\text { Humanistic } \\
\text { psychology } \\
\text { Ritual } \\
\text { Human } \\
\text { technology }\end{array}$ \\
\hline
\end{tabular}

Fig. 1. Images of Man Forming through the Processes of Re-ligio in the Three Aspects of Man's Total Space (adapted from [15, p.233].

Combining these inquiring approaches with spaces of inquiry we may suggest the following ways of knowledge creation and knowledge sharing for the inquiry into ICT and Social Informatics.

In order to act collectively it is our understanding that we need new guiding images. In The Image of the Futures, the Dutch sociologist Fred Polak [23], noted that when the dominant images of a culture are anticipatory, they 'lead' social development and provide direction for social change through a 'magnetic pull' toward the future. Markley [20, p. 214] explains:

"By their attractiveness and legitimacy they reinforce each movement that takes the society toward them, and thus they influence the social decisions that will bring them to realization. As a culture moves toward the achievement of goals inherent in its dominant images, the congruence increases between the images and the development of the culture itself - the implications of the images are explored, progress is made, and needs are more fully satisfied. [Illustrated in Fig. 2]

If the progress of the human system outstrips that of its traditional images, however, its policies and behavior (which are based on the old dominant images) becomes increasingly faulty - even counterproductive - precipitating a period of frustration, cultural disruption, or social crisis. The stage is then set for basic changes in the underlying images and the organization of the system. Various indicators suggest that our culture may now be nearing, if not at, such a stage."

It is thus our hypothesis that we need a new guiding image based on mythological and evolutionary approaches to social and spiritual space. This 
hypothesis tries to go ahead of Kant, Habermas and Derrida approach. At least that can be taken to be true for the Western World, yet one might wonder whether the dialogue might not better take the form of a dialogue between the Western World's methods and use of languages taken from rational approaches to physical (and partly social) space and an Eastern or Southern World's mythological and evolutionary methods and uses of language in social and spiritual spaces.

\section{Evolution of consciousness}

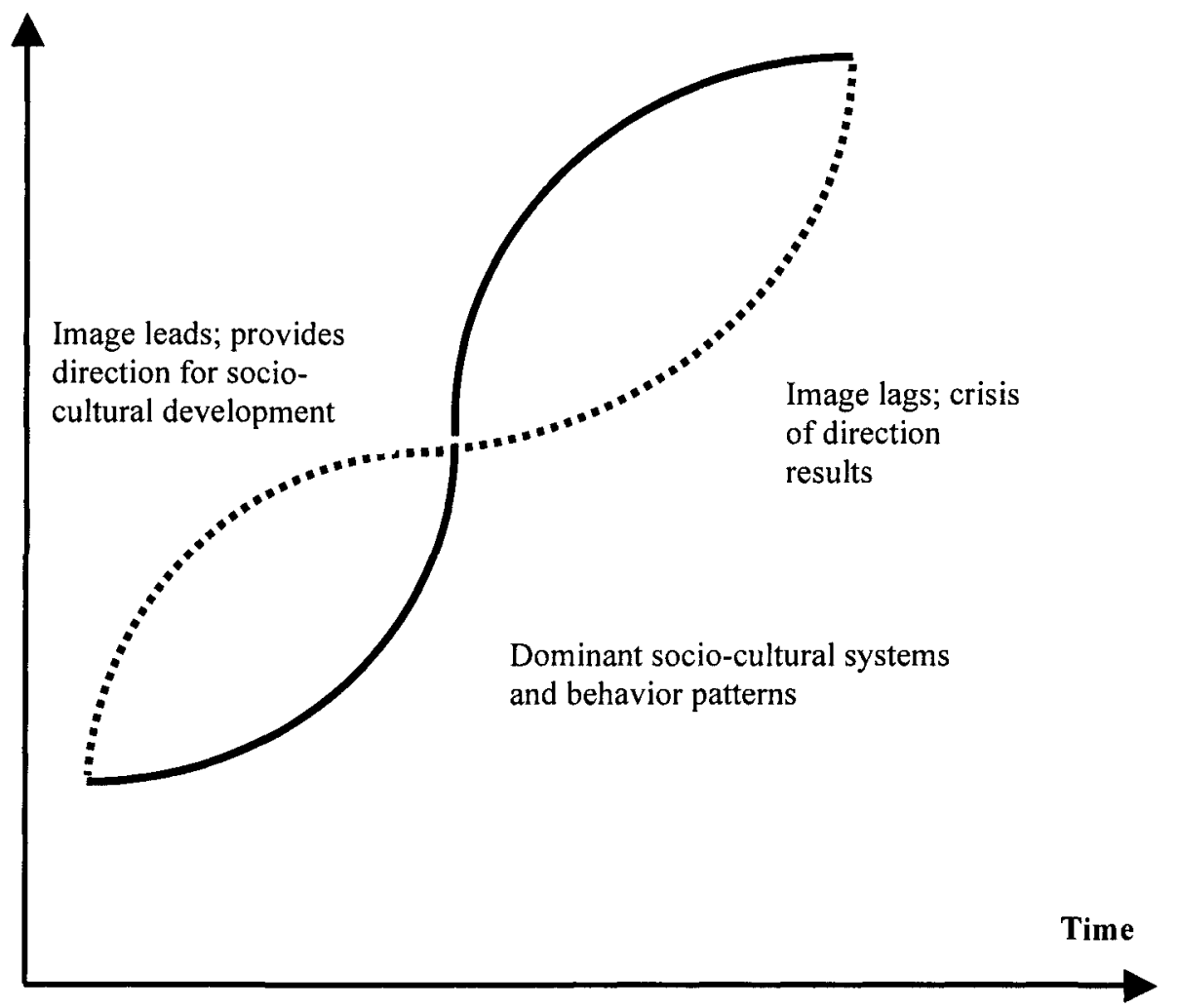

These mythological and evolutionary methods, need to surpass the debate of the simplification of the complexity of the social world. Following John Law [18, p. 152-3], some of the more obvious possibilities and challenges are:

- Process: In Euro-American method the bias is against process and in favour of product. If we look at any grant application form, the rules of method are imagined as a means to an end for knowing better or intervening. The practicalities of knowing are bracketed and treated as technique. So we should start of attending the mediations of method rather than being concentred in the final product. Means/ends divisions cut the cake in a particular way. Parts of process, enactment, can be pushed into a means/ends scheme, but others cannot. 
That means that we need to treat with the uncertainties and 'undecidables' of process as well as with means and ends.

- Symmetry: Instead of considering just one approach as good or bad (and the fixed ways and rules that they have to discovering realities), we should consider all practices of knowing as appropriate methods. We need to understand the different methods, so they have to be treated symmetrically, to explore them without, in the first instance, judging their adequacy in terms of our prior assumptions about what is methodologically right and what do not.

- Multiplicity: If we focus on practise then we are led to multiplicity since there are as many practises as many realities. Truth is no longer the only arbiter and reality is no longer destiny. There are choices to be made between the desirability of different realities. The world could always be otherwise. We need ways of knowing about and enacting fractionality or partial connection.

- Reflexivity: We need to ask whether we are able and willing to recognise that our methods also craft realities. It is necessary to be alert and aware that one method enacts divisions between different forms of absence: absence made manifest, and absence as Othering. So, boundaries made and remade, the point of view of the researcher/observer and his/her unavoidable complicity in realitymaking, and the situated context of knowing are central concern.

- Imaginaries: John Law suggests use allegory as a way of knowing the multiple and ambivalent, avoiding discourses about coherence or consistency. But this is just a beginning. Maybe the mythological and evolutionary level that we suggested in the fig. 1, can offer other metaphors and experiences of knowing that open our frameworks in order to create new possibilities of dialogue and understandings -even without oral or written language-. Flux, multiplicities, fractionalities, resonance, process of weaving, spirals, vortices, dances, passions, interferences, there are some of the metaphors for imaging creative methods and languages.

- Materialities: If we accept that possibility of imaginaries, then we should move beyond academic texts to texts in other modalities, and not just texts and figures, but bodies, devices, theatre, apprehensions, buildings, art, music, food. There is need for a whole range of materially innovative methods.

- Indefiniteness: Instead of expect definite results out methods, should, sometimes, perhaps often, manifest realities that are indefinite, and that as apart of this, allegory, non-coherence, and the indefinite are not necessarily signs of methodological failure.

If we agree there is not universal method, we have to think well about the modes of relating between sites and specificities. These are not split off from one another by 'external acts'. Science, politics and aesthetics, these do not inhabit different domains. Instead they interweave. Their relations intersect and resonate together in unexpected ways.

\section{References}

1. Apel, Karl-Otto (1999), Openly strategic uses of language: a transcendental-pragmatic perspective - a second attempt to think Habermas against Habermas, in Dews, Peter (ed.) (1999): Habermas - a Critical reader, Blackwell 
2. Boisot, Max (1995), Information Space, Routledge, London

3. Boisot, Max (1998), Knowledge Assets, Oxford University Press, New York

4. Bordum, Anders (2005), Immanul Kant, Jürgen Habermas and the categorical imperative, Philosophy \& Social Criticism, Vol. 31, no. 7, Nov., Sage Publ.

5. Borradori, Giovanna (2003), Philosophy in a time of terror - Dialogues with Jürgen Habermas and Jacques Derrida, University of Chicago Press

6. Callon, Michael (2002) Writing and (Re)writing devices as tools for managing complexity. In: Law, John; Mol Anne Marie (ed). Complexities. Social studies of knowledge practices. Duke University Press. Pp. 191-217.

7. Churchman, C.W. (1968), Challenge to Reason, McGraw Hill

8. Churchman.C.W. (1971), Design of Inquiring Systems, Basic Books

9. Derrida, Jacques (1986), De la gramatología. México: Ed. Siglo XXI, $4^{\text {a }}$. Ed.

10. Derrida, Jacques (1998), Espectros de Marx. El estado de la deuda, el trabajo del duelo y la nueva internacional. Madrid: Ed. Trotta. Original source: Specters of Marx, the state of the debt, the Work of Mourning, \& the New International, translated by Peggy Kamuf, Routledge 1994

11. Dews, Peter (ed.) (1999): Habermas - a Critical reader, Blackwell

12. Feyerabend, Paul (1975), Against Method, NLB, London

13. Foucault, Michel (1997), The Politics of Truth (ed. Sylvère Lotringer), Semiotext(e)

14. Habermas, Jürgen (2000), On the Pragmatics of Communication, (ed. Maeve Cooke), MIT Press

15. Hardt Michael; Negri Antoni (2003), Imperio, Buenos Aires: Paidós.

16. Jantsch, Eric (1975), Design For Evolution, Brazille

17. Jantsch, Eric (1976) Evolving Images of Man: Dynamic Guidance for the Mankind Process, in E. Jantsch C.H.Waddington: Evolution and Consciousness - Human systems in Transition, Addison-Wesley, 1976

18. Kant, Immanuel (1994), Ethical Philosophy: Grounding for the Metaphysics of Morals, Hackett

19. Kling, Rob et.al. (2000), Learning from Social Informatics: Information and Communication Technologies in Human Context (v 4.6, Aug. 2000), Center for Social Informatics, Indiana University

20. Law, John (2004). After method. Mess in social science research. Routledge, London Press.

21. Law, John; Mol Anne Marie (ed) (2002). Complexities. Social studies of knowledge practices. Duke University Press.

22. Markley, O.W. (1976) Consciousness in Transformation, in E. Jantsch C.H.Waddington: Evolution and Consciousness -- Human systems in Transition, Addison-Wesley, 1976

23. Negri, Antonio (2003), Time for revolution, Continuum, London

24. Prahalad, C.K. (2005), The Fortune from the Bottom of the Pyramid, Wharton School Publishing, Wupper Saddle River, NJ

25. Polak, Fred (1973) The Image of the Future, (E. Boulding transl., Abridged English ed., San Francisco, Jossey-Bass

26. Rasmussen L; Herlau, H; Rueda, R. (2004), ICT from the Bottom of the Pyramid, in: The Information Society: Emerging Landscapes, Zielinski, Chris, Duquenoy, Penny; Kimppa, Kai (Eds.), IFIP International Conference on Landscapes of ICT and Social Accountability, Turku, Finland, June 27-29, 2005, 354 p., ISBN: 0-387-30527-0IFIP, Springer Verlag, 2006

27. Singer, E.A. (1924), Mind as Behavior, R.G.Adams \& Co.

28. Singer, E.A. (1959), Experience and Reflection, University of Pennsylvania Press (C.W.Churchman ed.) 